Int. J. Electrochem. Sci., 15 (2020) 11929 - 11946

International Journal of

ELECTROCHEMICAL

SCIENCE

WWW.electrochemsci.org

\title{
Study on Performance of Electrocatalytic Dechlorination of 2, 5 - dichloronitrobenzene by Copper and Palladium Bimetallic Composites Modified Ti Electrode in Aqueous Solution
}

\author{
He Xu ${ }^{1, *}$, Aili Lit ${ }^{1}$, Zhongyi $\mathrm{Gu}^{2}$, Jianshe Liu ${ }^{1}$ Jinli Qiao $^{1}$ \\ ${ }^{1}$ College of Environmental Science and Engineering, Donghua University, Shanghai 201620, PR \\ China \\ ${ }^{2}$ Technical Center for Industrial Product and Raw Material Inspection and Testing of Shanghai \\ Customs, Shanghai, 200002, PR China \\ *E-mail: hexu@dhu.edu.cn
}

doi: $10.20964 / 2020.12 .59$

Received: 14 August 2020 / Accepted: 23 September 2020 / Published: 31 October 2020

\begin{abstract}
In our work, a facile copper and palladium composites modified $\mathrm{Ti}$ electrode $(\mathrm{Cu}-\mathrm{Pd} / \mathrm{Ti})$ was prepared by electrochemical deposition and chemical replacement method, which was applied for electrocatalytic dechlorination of 2, 5-Dichloronitrobenzene (2, 5-DCNB), a typical organic chloride pollutant. The morphologies and structures of $\mathrm{Cu}-\mathrm{Pd} / \mathrm{Ti}$ were characterized by scanning electron microscopy (SEM), X-ray diffraction (XRD), and X-ray photoelectron spectroscopy (XPS). The electrochemical performance was examined by cyclic voltammetry (CV) and linear sweep voltammetry (LSV). The experimental results displayed that $\mathrm{Cu}$ polyhedrons were formed at the Ti electrode surface $(\mathrm{Cu} / \mathrm{Ti})$ and the palladium metals were mainly coated at $\mathrm{Cu} / \mathrm{Ti}$ electrode in the zero-valent and divalent states. Meanwhile, the copper-palladium composites were uniformly dispersed at the Ti electrode surface. The electrochemical experiments verified that $\mathrm{Cu}-\mathrm{Pd} / \mathrm{Ti}$ composite electrode exhibited high catalytic dechlorination property and large electrochemical active surface area (EASA) owning to the cooperative interaction of $\mathrm{Cu}$ and $\mathrm{Pd}$ composites materials. The $\mathrm{Cu}-\mathrm{Pd} / \mathrm{Ti}$ displayed better electrocatalytic efficiency towards 2, 5-DCNB reduction than that of the other electrodes in this experiment. With a current density of $2.25 \mathrm{~mA} / \mathrm{cm}^{2}$, the electro-reductive removal rate of 2-DCNB reached $97.1 \%$ within 3 hours. The intermediates and mechanisms of dechlorination were identified through high-performance liquid chromatography (HPLC) and gas chromatography coupled with mass spectrometry (GC-MS), and the main final products were properly transformed to aniline. This work may provide a beneficial choice for the effective treatment of DCNBs in the environment.
\end{abstract}

Keywords: Electrocatalytic dechlorination, Electrochemical degradation, Chloro-nitrobenzene compounds, $\mathrm{Cu}-\mathrm{Pd}$ bimetallic composites 
(C) 2020 The Authors. Published by ESG (www.electrochemsci.org). This article is an open access article distributed under the terms and conditions of the Creative Commons Attribution license (http://creativecommons.org/licenses/by/4.0/). 